\title{
SUSTAINABLE URBAN MOBILITY AND URBAN SAFETY AND SECURITY: A CASE STUDY OF THE CITY CENTRE OF GENOA, ITALY
}

\author{
SELENA CANDIA, FRANCESCA PIRLONE \& ILENIA SPADARO \\ DICCA Department of Civil, Chemical and Environmental Engineering, Genoa University, Italy
}

\begin{abstract}
The SUMP - Sustainable Urban Mobility Plan - introduced by the European Union in 2013, is a strategic mobility tool intended to promote sustainable activities at an urban level. The SUMP wants to improve the quality of life of citizens and to involve people and stakeholders in the decision-making process. The "Bremen Declaration on Sustainable Urban Mobility Planning in Europe" (2016), has definitely defined that a good SUMP should: integrate the mobility planning into urban planning; support environmental, social and economic sustainability; and adopt an urban vision giving priority to people rather than vehicles, promoting pedestrian and cycling mobility. The paper joins the ongoing debate on sustainable mobility considering another aspect that should be included in the SUMP: urban safety and security. The authors put into relation the concepts of safety and security with the concept of sustainability. Currently, also the most innovative plans consider urban safety and security only with regard to road accidents. Although this last aspect is of paramount importance, we should be careful not to overlook a more global approach to safety and security. A place is considered safe in relation to its crime rate, risk perception, environmental or social degradation. The research intends to define a new approach that considers a rather broader and deeper view of the issue of urban safety and security within the SUMP. The methodological approach initially uses the SWOT (Strengths, Weakness, Opportunities and Threats) analysis to investigate the state-of-the-art of the SUMPS toll. The authors identified a series of indicators - objective and subjective - to measure urban safety and security. Subjective indicator aims at quantifying the perception of risk by the population, which lives, studies, works in the urban area under study. Finally, the authors applied the methodology proposed in this article to the city centre of Genoa.
\end{abstract}

Keywords: PUMS, sustainable mobility, urban safety and security.

\section{INTRODUCTION}

The Sustainable Urban Mobility Plan - SUMP - is a strategic tool relating to urban transport and mobility intended to promote sustainable activities and practices at the urban level. The European Commission introduced the SUMP in 2013 to update the previous tool in the field of urban mobility: the UMP - Urban Mobility Plan. In contrast to traditional transport planning approaches, the SUMP considers policies actions to enhance environmental, political and social sustainability. "A Sustainable Urban Mobility Plan has as its central goal improving accessibility of urban areas and providing high-quality and sustainable mobility and transport to, through and within the urban area. It regards the needs of the "functioning city" and its hinterland rather than a municipal administrative region" [1]. Urban mobility planning is a complex and contradictory task. It takes into account different needs relating to the local level and integrates policies between many sectors (land use, transport, economic, environment, energy...) across different levels of government and administration. Planners have to respond to many, often opposite, demands: restricting traffic in old town centres and ensuring the movements of goods and people; sustaining a high quality of life and maintaining an attractive environment for business.

The Sustainable Urban Mobility Plan contributes to reaching the European climate and energy objectives and addresses transport-related challenges and problems of urban areas in 
a more sustainable and integrative way. The SUMP wants to improve the quality of life of citizens and to involve people and stakeholders in the decision-making process. This plan aims at meeting people's needs, cars' needs are less important. "If you plan cities for cars and traffic, you get cars and traffic. If you plan for people and places, you get people and places" [2]. To achieve this goal, it is important to ensure that the different modes of transport are not programmed individually but aggregated in a perspective of inter-modality and it is also necessary to conceive the planning of mobility and transport as a shared policy, serving the different needs of society (economic, social, environmental) [3].

According to the traditional planning tool - the UMP - the local authorities (municipalities, metropolitan cities, macro-regions) define and apply strategies to enhance urban mobility in their territories over a medium/long-term period. The Italian government introduced the UMP with the law 340/2000. This plan seeks to contribute to development of an urban transport system which:

- Satisfies the mobility needs of the population;

- Ensures adequate standards of service and accessibility;

- Reduces the noise and air pollution;

- Reduces energy consumption;

- Increases safety levels in transport and road traffic;

- Minimizes the individual use of the private car;

- Reduces the congestion phenomena;

- Increases the percentage of citizens which use the public transport.

Due to the introduction of the SUMP at the European level, many Italian municipalities and metropolitan cities are updating their mobility plans. The SUMP is also a medium/longterm strategic tool (over 10 year) relating to urban mobility but it intended to increase sustainable mobility solutions. It is therefore evident that many of the objectives and interventions supported by the SUMP are in agreement with the UMP's contents. The optimization of the urban mobility system is an unavoidable objective to contribute to the fight against climate change at the global level and to the fight against the air pollution at the local level. To reach the environmental objectives set by the European Union, local governments are supporting actions change the way goods and people travel. The SUMP encourages citizens to behave in more sustainable ways and supports decisions in favour of preferable travel options. To do this, the plan faces with the other urban planning tools (landuse planning, environment planning...). Indeed, the SUMP should not be considered as "yet another plan" but it should integrate existing planning practices. European strategies on urban mobility indicate the SUMP as the essential tool for stimulating policy change and encouraging a shift toward sustainable transportation modes. For this reason, the European Union gives incentives for local authorities for the creation of such plans.

Table 1 shows the main differences between the traditional transport planning approaches and the new Sustainable Urban Mobility Plan [1].

The "Bremen Declaration on Sustainable Urban Mobility Planning in Europe" [4] (April 2016), has definitely defined that a good SUMP should:

- Integrate the mobility planning into the urban planning;

- Support environmental, social and economic sustainability;

- Adopt an urban vision giving priority to people rather than vehicles, promoting pedestrian and cycling mobility. 
Table 1: The main differences between the Sustainable Urban Mobility Plan and a more "traditional" planning process.

\begin{tabular}{|c|c|c|}
\hline $\begin{array}{l}\text { Traditional transport } \\
\text { planning }\end{array}$ & & SUMP \\
\hline Focus on traffic & $\rightarrow$ & Focus on people \\
\hline $\begin{array}{l}\text { Primary objectives: } \\
\text { Traffic flow capacity and peed }\end{array}$ & $\rightarrow$ & $\begin{array}{l}\text { Primary objectives: Accessibility and quality of } \\
\text { life, as well as sustainability, economic viability, } \\
\text { social equity, health and environmental quality. }\end{array}$ \\
\hline Modal-focussed & $\rightarrow$ & $\begin{array}{l}\text { Balanced development of all relevant transport } \\
\text { modes and shift towards cleaner and more } \\
\text { sustainable transport modes. }\end{array}$ \\
\hline Infrastructure focus & $\rightarrow$ & $\begin{array}{l}\text { Integrated set of actions to achieve cost-effective } \\
\text { Solutions. }\end{array}$ \\
\hline Sectorial planning document & $\rightarrow$ & $\begin{array}{l}\text { Sectorial planning document that is consistent and } \\
\text { complementary to related policy areas (such as } \\
\text { land use and spatial planning; social services; } \\
\text { health; etc.) }\end{array}$ \\
\hline $\begin{array}{l}\text { Short- and medium-term } \\
\text { delivery plan }\end{array}$ & $\rightarrow$ & $\begin{array}{l}\text { Short- and medium-term delivery plan embedded } \\
\text { in a long-term vision and strategy }\end{array}$ \\
\hline $\begin{array}{l}\text { Related to an administrative } \\
\text { area }\end{array}$ & $\rightarrow$ & $\begin{array}{l}\text { Related to a functioning area based on travel-to- } \\
\text { work patterns. }\end{array}$ \\
\hline Domain of traffic engineers & $\rightarrow$ & Interdisciplinary planning teams \\
\hline Planning by experts & $\rightarrow$ & $\begin{array}{l}\text { Planning with the involvement of stakeholders } \\
\text { using a transparent and participatory approach. }\end{array}$ \\
\hline Limited impact assessment & $\rightarrow$ & $\begin{array}{l}\text { Regular monitoring and evaluation of impacts to } \\
\text { inform a structured learning and improvement } \\
\text { process. }\end{array}$ \\
\hline
\end{tabular}

This declaration, presented at the third Annual European Conference on Sustainable Urban Mobility Planning, focused on an efficient and people-focussed city as a core objective of Sustainable Urban Mobility Planning. This declaration, indeed, states the following eight points to be followed by urban planners: 1) When talking about transport efficiency, look first at efficient use of street space; 2) Put people ahead of vehicles; 3) Address the changing transport challenges for business; 4) Plan your city and its mobility together; 5) Consider simple solutions first and use technology appropriately; 6) Put use ahead of ownership; 7) Enable people to participate in shaping their city; 8) Be prepared to face future challenges.

In addition to the above mentioned points, the SUMP should be designed in compliance with the other urban plans and processes and it should ensure the collaboration between relevant policy areas and authorities. This process also should seek to guarantee the involvement of stakeholders (citizens, associations, local institutions...) at appropriate stages. Local authorities have to organize meetings, forum and workshop to design and explore with the local community and the main stakeholders new policies and regulations in real-life scenarios. Citizens - as travellers, business people, consumers, costumers... - should be considered the focus of the plan because the future of a city depends on its inhabitants. People must be part of the solution and the SUMP is a plan for people. In the meanwhile, it is crucial to promote a new mobility culture in cities, through educational activities, awareness programs, addressed to all age groups (children, young people, elderly...). 
Residents usually depend very much on their car and therefore the SUMP should establish new measures to promote sustainable mobility. The local authorities should influence travel decisions without limiting freedom of choice. Soft mobility, public transportation and share mobility (car-pooling, bike/car-sharing...) are the best solutions. However, one solution does not exclude the other. For this reason, intermodal aspects are important. Inter-modality combines the strengths of different transportation options and reduces the automobile dependency by increasing the use of public transport. For this reason, a Sustainable Urban Mobility Plan promotes the development of all relevant transport modes (sustainable solutions and less sustainable solutions such as cars), while encouraging a shift towards more sustainable modes.

In line with the logic of the smart-city, it is important to enhance the role of technology to optimize and innovate the transportation services. Smart technology has undergone something of a revolution in recent years. The internet-of-things has already come to influence mobility aspects. To explore the latest in smart technology and IT solutions, it is important to raise the quality of life in an urban area.

Mobility therefore turns out to be a connective and transversal topic to the different urban themes and plans. This aspect must be kept in mind when preparing a new urban mobility plan (see Fig. 1).

But what is the real link between sustainability (considering the environmental, economic and social aspects) and the SUMP? Currently the existing SUMP addresses the environmental aspects in terms of: pollution produced by the transport sector, reduction of $\mathrm{CO} 2$ emissions and noise, air quality improvement and congestion reduction. Therefore, the SUMP promotes environmentally friendly mobility supporting measures to encourage public transport, walking and cycling. From an economic point of view, the goal is to find a balance between costs and benefits. The SUMP should contain a review of costs and benefits of all transport modes taking into account of the wider societal costs and benefits. This analysis is necessary to improve the efficiency and cost-effectiveness of the transportation of persons and goods. Finally, as regards the social aspect, the SUMP aims at making urban areas safer and more accessible for the generations of today and tomorrow. It directly contributes to enhancing the attractiveness and the quality of life and the urban environment for the benefits of citizens, the economy and society as a whole. In the context of SUMP, quality of life has been expressed as "space for people, better air, less noise, improved health and reduced health cost, ecosystem health, less traffic, less pollution, time and cost savings of sustainable urban mobility solutions" [5].

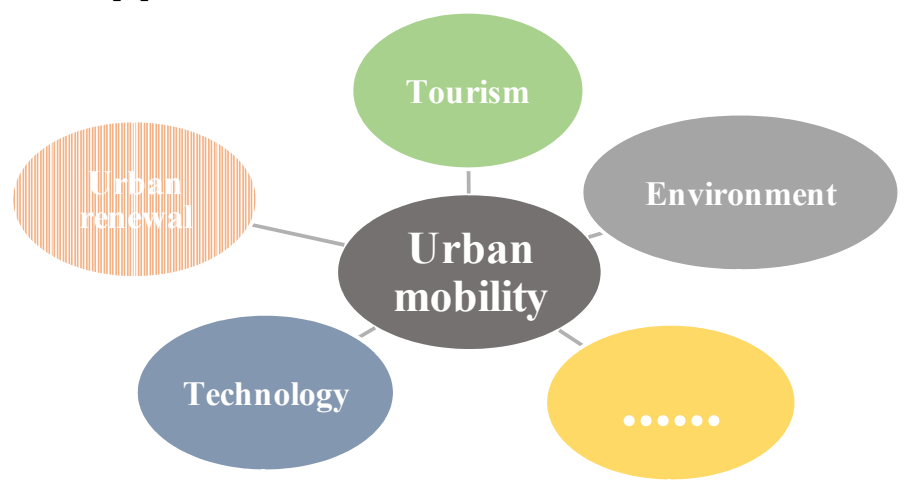

Figure 1: The mobility issue and its connections with other urban topics. 


\section{THE SECURITY IN THE PUMS}

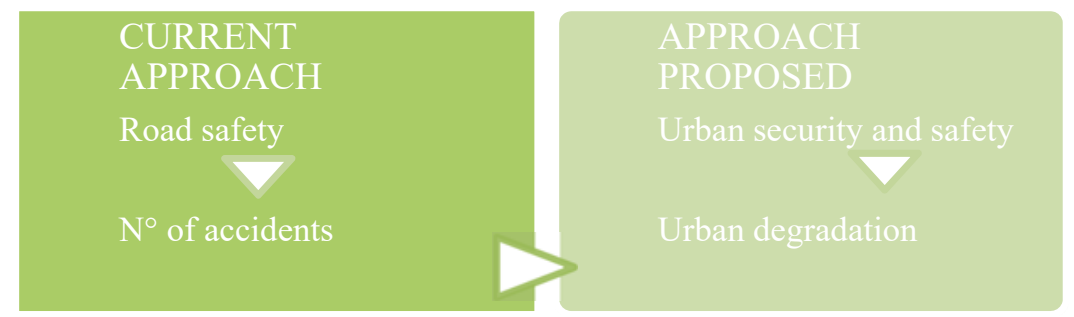

Figure 2: Methodological approach: urban safety and security and the SUMP.

\section{THE SUMP AND URBAN SAFETY AND SECURITY: THE NEW APPROACH PROPOSED}

The paper joins the ongoing debate on sustainable mobility considering another aspect that should be included in the SUMP: urban safety and security. The authors put into relation the concepts of safety and security with the concept of sustainability. Currently, also the most innovative plans consider urban safety and security only with regard to road accidents. Although this last aspect is of paramount importance, we should be careful not to overlook a more global approach to safety and security. A place is considered safe in relation to its crime rate, risk perception, environmental or social degradation.

The acceptability of risk strictly depends on its perception, or rather, on the perception of a danger. "Although risk and danger are two different concepts, many people (especially nonexpert people) indiscriminately use these terms. The danger is related to a subjective judgement and corresponds to the fear of being involved in a negative situation. The risk asses the possibility that something bad, unpleasant, or dangerous may happen" (Ippolito, 1994). For this reason, there is also a distinction between the risk perceived and the objective risk. According to the sociologist Luhman, one of the main reasons that made relevant the concept of "perceived risk" in the contemporary world lies in the fact that "the future of our societies increasingly depends on the social decisions" [6].

In the guidelines "Developing and implementing a Sustainable Urban Mobility Plan", the European Union wonders in which kind of city we want to live in. The question implies the need to define an urban framework where transport and mobility are integral part of part the urban and social development of a city taking into consideration also economic, environmental, health and safety/security issues.

Among the most pressing challenges faced by urban mobility, there is the design of a healthy and safe environment for a better quality of life in cities and their surroundings. The term environment refers to a set of social, cultural and moral conditions, under which a human being develops his personality. It is also important to clarify the terms security and safety: security is the prevention of intentional unpleasant activities by people - such as robbery, mugging, terrorist activities, etc.; safety is the prevention of not intentional accidents - such as floods, earthquakes, and accidents at work... "The basic idea of both is protecting assets from hazards/threats creating safe/secure conditions. The condition safety is about being protected, while the condition security is about being free from danger" [7]. From this definition, is evident that safety and security are closely linked to sustainability. A city can be considered sustainable only if is safe and secure. Security and safety are therefore essential conditions for the development of human life, freedom and solidarity. Security and safety do not only concern the lives of individuals but also the life of the city. A sustainable urban 
development model should consider safety and security as primary services for the local community. In the literature, social sustainability is defined as the ability of guarantee, in the most impartial and widespread way possible, even to the weakest subjects, a good accessibility to all city functions; therefore social sustainability implies a safe and accessible urban mobility. The OECD - Organization for Economic Cooperation and Development recognizes urban safety and security fundamental to improve the quality of life (see Fig. 3).

"Urban security refers to the livability and decorum of a city. It is possible to improve urban safety and security through reclassification operations, social interventions, cultural activities, recovery plans for degraded areas or sites and the affirmation of higher levels of social cohesion and civil cohabitation" [9].

Currently, also the most innovative plans consider urban safety and security only with regard to road accidents. Although this last aspect is of paramount importance, we should be careful not to overlook a more global approach to safety and security. A place is considered safe in relation to its crime rate, risk perception, environmental or social degradation. The research intends to define a new approach that considers a rather broader and deeper view of the issue of urban safety and security within the SUMPS. The final goal is to promote sustainability and to improve the quality of life of citizens, making public spaces more attractive and raising the level of trust in local authorities of the population.

The first phase of the methodological approach is the one related to the analysis tools. In order to have a correct analysis of the current situation, the authors used the SWOT (Strengths, Weakness, Opportunities and Threats) analysis to investigate the strengths and weaknesses of the area under study, offering an overall picture of the pilot site. In the second stage, the authors identified a series of indicators - objective and subjective - to measure urban safety and security. Subjective indicators aims at quantifying the perception of risk by the population, which lives, studies, works in the urban area under study. In particular, two types of indicators have been defined: safety/security indicators and neglect/degradation indicators; both provide objective and subjective aspects (see Table 2).

For each indicator, the authors defined a specific form with a short description, the source of information and the unit of measurement. The authors also prepared a questionnaire to collect subjective data. This tool is composed of different closed-ended questions aimed at investigating: the profile of the respondent sample (age, sex, residence); the risk perception; the urban neglect perception; the social and environmental degradation perception.
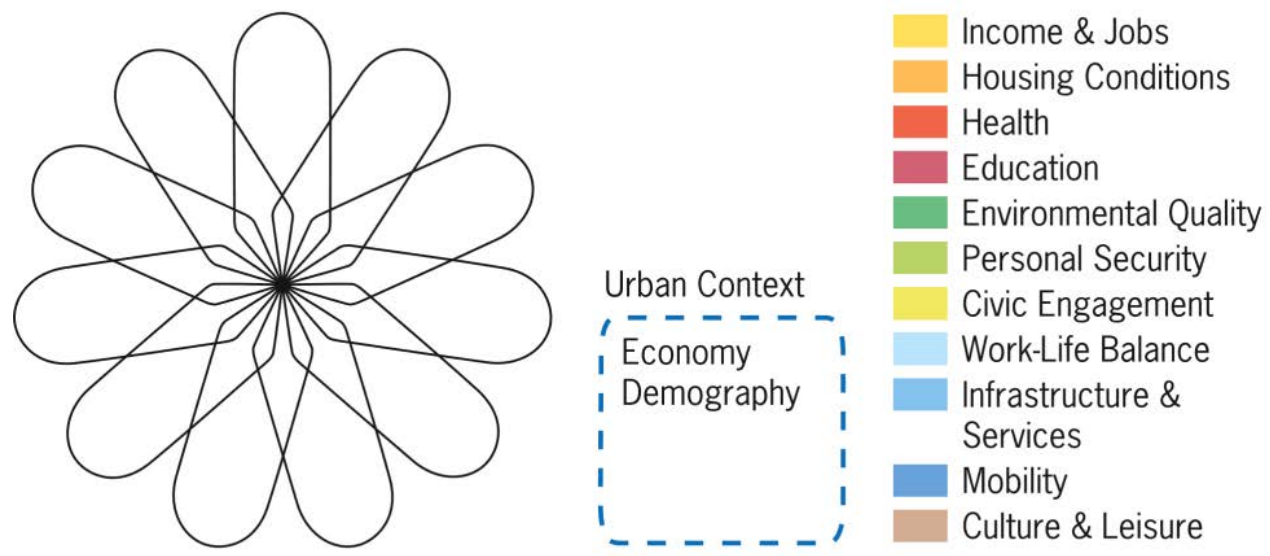

Figure 3: Quality of life dimensions [8]. 
Table 2: Methodological approach: the authors identified a series of indicators - objective and subjective - to measure urban safety and security and urban neglect and degradation.

\begin{tabular}{|c|c|}
\hline $\begin{array}{l}\text { A - Objective indicators for urban safety } \\
\text { and security } \\
\text { (Elaboration of Istat data) }\end{array}$ & $\begin{array}{ll}\text { - } & \text { Murder } \\
\text { - } & \text { Theft } \\
\text { - } & \text { Robbery } \\
\text { - } & \text { Petty crime }\end{array}$ \\
\hline $\begin{array}{l}\text { B-Subjective indicators for urban safety } \\
\text { and security (The authors prepared and } \\
\text { distributed a specific questionnaire) }\end{array}$ & $\begin{array}{ll} & \text { Day life } \\
\text { - } & \text { Night life } \\
\text { - } & \text { Fear of crime } \\
\end{array}$ \\
\hline $\begin{array}{l}\mathrm{C}-\text { Objective indicators for neglect } \\
\text { (Technical survey of the pilot area) }\end{array}$ & $\begin{array}{l}\text { - } \text { Street lighting } \\
\text { - Highways and street furniture } \\
\text { maintenance } \\
\text { - } \text { Architectural barriers and accessibility }\end{array}$ \\
\hline $\begin{array}{l}\text { D - Subjective indicators for neglect } \\
\text { (The authors prepared and distributed a } \\
\text { specific questionnaire) }\end{array}$ & $\begin{array}{ll}\text { - } & \text { Social degradation perceived } \\
\text { - } & \text { Street lighting perceived } \\
\text { - } & \text { Maintenance perceived } \\
\text { - } & \text { Architectural barriers and accessibility } \\
& \text { perceived }\end{array}$ \\
\hline
\end{tabular}

$\square$ Male
$\square$ Female
Age
$\square$ 14-24
$\square 15-34$
$\square 35-44$
$\square 44-54$
$\square 55-64$
$\square$ over 65
Do you live in the
city centre?
$\square$ yes
$\square$ no
Do you work or
study in the city
centre?
$\square$ yes
$\square$ no
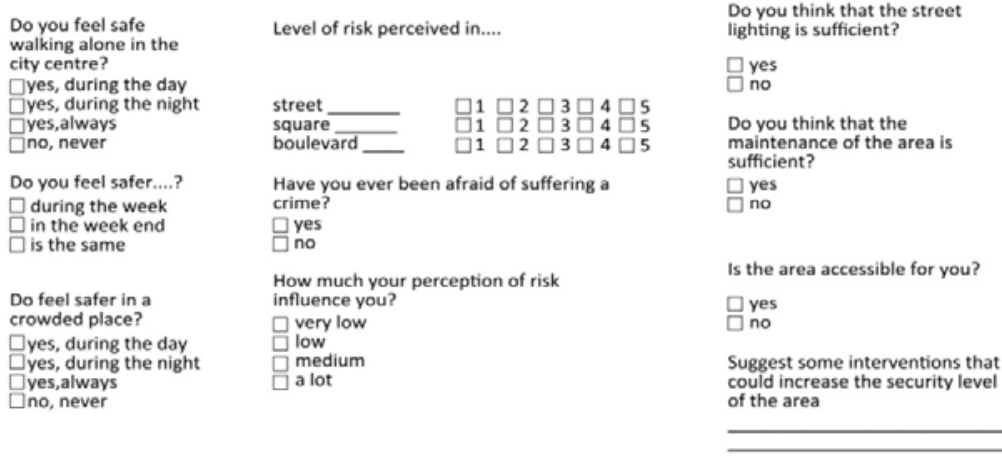

Figure 4: Methodological approach: questionnaire realized to measure subjective indicators.

At the end of the questionnaire, there is an open-ended questions about the interventions requested to improve the urban safety and security of the pilot area (see Fig. 4).

The authors collected and processed the data and the gathered information using a special database. On the basis of the results obtained, the authors defined different sustainability maps (each one with a specific legend) aimed at highlighting the most critical areas(characterized by higher levels of risk) in order to define the best actions to be implemented in the pilot area.

\section{URBAN SECURITY AND SAFETY FOR THE SUMP OF GENOA: CASE STUDY - THE CITY CENTRE OF GENOA}

The methodological approach proposed by the paper aims at including a rather broader and deeper view of the issue of urban safety and security within the SUMPS. The authors studied a first application to a specific case: the city centre of Genoa. 
The city centre of Genoa is considered one of the largest historical centre in Europe. It is characterized by narrow streets, magnificent buildings, ancient churches, cobbled paths and historical shops selling tripe, poultry and salt cod. In the middle of the city centre there is the old port area, renewed in 1992 during the 500th anniversary of the discovery of America by Cristoforo Colombo, a Genoese explorer. Thanks to its port, Genoa has always been a cross roads of cultures and peoples. In 2004, Genoa was "European Capital of Culture" and in 2006 its system of "Palazzi dei Rolli e delle Strade Nuove" was inscribed on the UNESCO World Heritage List.

The urban fabric make it difficult to use cars (most of the city centre is a pedestrian zone) and to control the territory. In some areas inside the old town centre, the rate of criminality infects the social and commercial environment. In particular, the area of Via Balbi, near Genoa Piazza Principe Railway Station, is an important example of how the risk perceived influences the choices of mobility of the citizens. In fact, the population to reach Via Gramsci, a street that runs parallel to Via Balbi, prefers to walk right down the street rather than crossing the historic centre that is located between this two streets.

In this context, the SUMP tool could be use to make the city more attractive and secure. "There are many international examples that clearly show how is possible to evolve modern city into more liveable spaces. It is possible to tackle the overwhelming challenges of this urban age supporting sustainable mobility" [10]. Before defining the new SUMP for Genoa, the authors analysed - using the SWOT methodology (Table 3) - the strengths and the weakness of Genoa old town and the opportunities and the threats related to the global market and changes.

Subsequently, the authors defined objective and subjective indicators. Unfortunately, it was not possible to quantify some indicators related to petty crimes because of the protection of sensitive data. Thanks to a questionnaire, the authors collected the subjective data.

Table 3: SWOT Analysis of the city centre of Genoa.

\begin{tabular}{|c|c|}
\hline Strengths & Weaknesses \\
\hline $\begin{array}{l}\text { - Place of a great historical and } \\
\text { commercial interest } \\
\text { - } \quad \text { Part of the pilot area is inscribed on } \\
\text { the UNESCO world heritage list } \\
\text { - Good pedestrian accessibility } \\
\text { - } \quad \text { Great touristic interest } \\
\text { - Crossroad of culture and people }\end{array}$ & $\begin{array}{ll}\text { - } & \text { Petty crime } \\
\text { - } & \text { Degraded public spaces } \\
\text { - } & \text { Poor lightning } \\
\text { - } & \text { Cobbled path } \\
\text { - } & \text { Difficulty in collecting waste and } \\
\text { cleaning the narrow streets } \\
\text { - Variable social fabric (students, } \\
\text { immigrants, workers) }\end{array}$ \\
\hline Opportunities & Threats \\
\hline $\begin{array}{l}\text { - New planning tools such as the } \\
\text { SUMP to improve the quality of life } \\
\text { in the city } \\
\text { - } \quad \text { Growth in tourism industry } \\
\text { - New technologies and ICT systems } \\
\text { - } \quad \text { EU funds to revitalize old town centre } \\
\text { - Soft mobility }\end{array}$ & $\begin{array}{l}\text { - Global economic crisis (many shops } \\
\text { are forced to close) } \\
\text { - Less public investments in old town } \\
\text { centre } \\
\text { - Clime chance (more frequent } \\
\text { accidents such as flood) }\end{array}$ \\
\hline
\end{tabular}


All the information received and collected had been processed using a database [11], [12]. Thanks to the results obtained, the authors defined different maps to improve the quality of life and the sustainability of the old town of Genoa.

According to the methodological approach proposed, the objective data had been compared with the subjective data. For example, with regard to street lighting, the authors conducted a specific technical survey to report all the streets with inadequate and badly positioned lighting. After that on a map have been reported the streets indicated by people dangerous because of bad or poor lighting. It is not surprising, that often objective and subjective data are contradictory. Also the risk level connected to bad lighting is different. People feel unsafe and vulnerable in crossing a dark street, and they perceive themselves to be at risk. The risk perceived is higher that the objective risk (see Fig. 5).

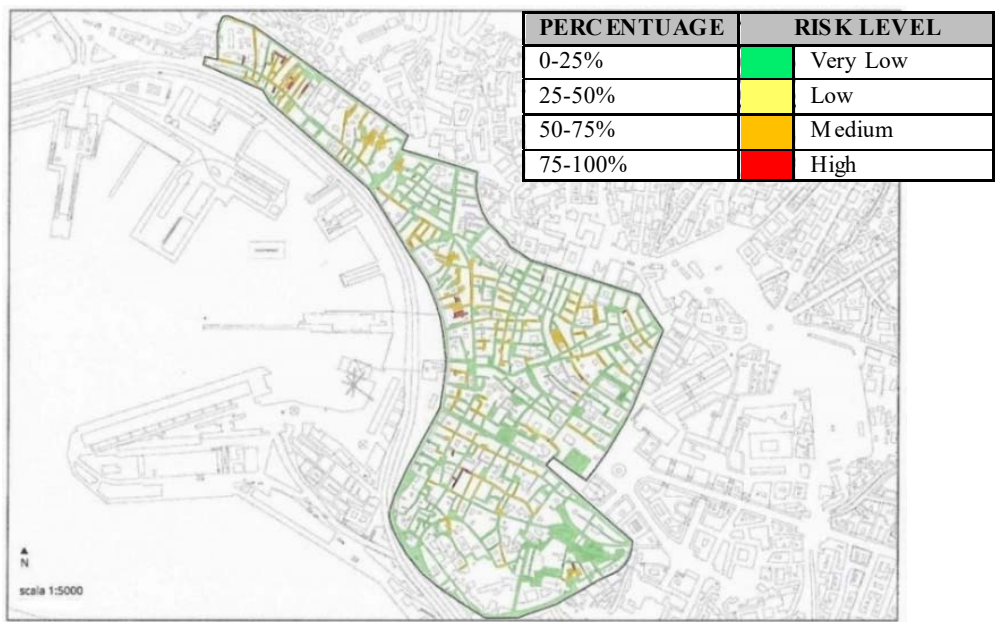

Figure 5: This map show the state of art of street lighting inside the old town centre of Genoa.

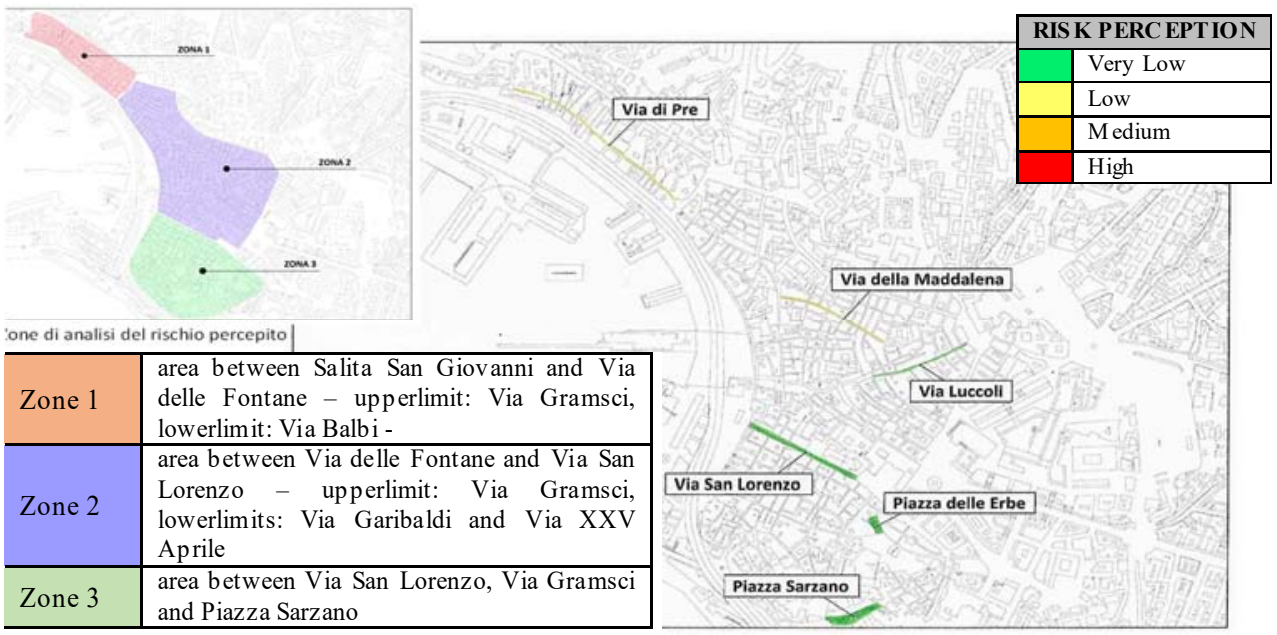

Figure 6: Risk perception during the day. 
The same cannot be said for the perception of risk relating to accessibility. In this case the respondent sample perceived a lower risk.

In doing this research, the authors considered three areas inside the old town centre of Genoa. Each area has its specific characteristics and indicators.

It is also interesting to see the overall scenario of risk perception during the day and the night. For example, in Fig. 6 it is possible to see the risk perceived during the day by the respondent sample.

Finally, starting from the results highlighted in the above-mentioned maps, the authors defined different typologies of interventions that should be implemented to revitalize the old town centre of Genoa (see Table 4). Some of this interventions were directly suggested by the respondent sample.

Table 4: Typologies of interventions that should be implemented to revitalize the old town centre of Genoa.

\begin{tabular}{|c|c|c|}
\hline Indicator & Risk levels & Interventions suggested \\
\hline 1. Murder & Minimal & More surveillance \\
\hline 2. Theft & Low & More surveillance \\
\hline 3. Robbery & Minimal & More surveillance \\
\hline 4. Petty crime & Minimal & More surveillance \\
\hline 5. Day life & Minimal & $\begin{array}{l}\text { During the day the risk perceived is very } \\
\text { low. However, some areas of the old town } \\
\text { centre of Genoa are sparsely populated } \\
\text { during the day. We suggest to introduce } \\
\text { wi-fi areas and some benches. }\end{array}$ \\
\hline 6. Night life & Medium & $\begin{array}{l}\text { Thematic tours, new functions for } \\
\text { degraded streets and squares. New pubs } \\
\text { and restaurants to enhance the "movida". }\end{array}$ \\
\hline 7. Fear of crimes & Low & More surveillance \\
\hline 8. Street lightning & Low & $\begin{array}{l}\text { New streetlamps, LED systems, smart } \\
\text { lightning }\end{array}$ \\
\hline $\begin{array}{l}\text { 9. Urban management/ } \\
\text { maintenance }\end{array}$ & Low & Revitalisation of abandoned urban spaces \\
\hline 10. Accessibility & Minimum & $\begin{array}{l}\text { Better accessibility for all (young, disabled } \\
\text { people, elderly...) }\end{array}$ \\
\hline $\begin{array}{l}\text { 11. Perception of urban } \\
\text { decay }\end{array}$ & High & Improved the sense of civic duty \\
\hline $\begin{array}{l}\text { 12. Perception of street } \\
\text { lighting }\end{array}$ & High & Improve the street lighting \\
\hline $\begin{array}{l}\text { 13. Perception of urban } \\
\text { maintenance } \\
\text { management strategy }\end{array}$ & High & Waste management, street cleaning... \\
\hline $\begin{array}{l}\text { 14. Perception of } \\
\text { accessibility }\end{array}$ & Minimum & $\begin{array}{l}\text { Better accessibility for all (young, disabled } \\
\text { people, elderly...); coloured installations }\end{array}$ \\
\hline
\end{tabular}




\section{CONCLUSIONS}

Thanks to the research proposed by this paper, it has been possible to develop a general, replicable and universal approach that can be applied to different realities. The idea is to consider a rather broader and deeper view of the issue of urban safety and security within the SUMP - Sustainable Urban Mobility plan. To improve urban security and safety is essential to understand the real risk and the risk perceived. This is because the main purpose of this paper is to design a city for people and with people. Broader participation and engagement of key stakeholders and citizens have gained greater importance in the last decades. The SUMP focuses on people and meets their basic mobility needs. But to real improve the quality of life of European citizens we need to address urban safety and security. For this reason, the authors put into relation the concepts of safety and security with the concept of sustainable mobility. Currently, also the most innovative SUMP consider urban safety and security only with regard to road accidents. Although this last aspect is of paramount importance, we should be careful not to overlook a more global approach to safety and security. A place is considered safe in relation to its crime rate, risk perception, environmental or social degradation.

Starting from the results obtained by this research, it is evident that it is necessary to implement strategies that will contribute to the city's future economy, sustainability and overall health, hence citizens' wellbeing and happiness. The SUMP is the ideal tool to contribute to enhancing the attractiveness and quality of the urban environment. In this perspective, it is therefore necessary to cooperate and co-design with citizens the city of the future by adopting a participatory planning strategy which brings citizens and other stakeholders on board from the outset and throughout the plan development and implementation process.

Thanks to the new PUMS, is possible to increase the liveability and the quality of public spaces, encouraging pedestrian and cycle mobility but in the meantime is also possible to increase urban security and safety.

\section{APPENDIX}

- F. Pirlone studied in deep the concept of urban safety and security. She suggested how to integrate this topic into the Sustainable Uban Mobility Plan tool. The author also defined the different aspects of sustainability that should be included in the SUMP.

- I. Spadaro described the sustainable urban mobility plan in the international and Italian context. She analysed the different SUMP adopted by the main Italian cities. She also investigated the participatory approach promoted by the SUMP.

- S. Candia focused on the case study: the old town centre of Genoa. She defined the objective and subjective indicators used to realize the different thematic map described in the penultimate section. She also studied how urban mobility could be useful to revitalize historical centres.

\section{REFERENCES}

[1] European Commission, 2013, Guidelines developing and implementing a Sustainable urban mobility plan. European Platform on Sustainable Urban Mobility Plans.

[2] Kent, F., 2005, Streets are People Places, Project for public space.

[3] Pirlone, F. \& Spadaro I., 2017, Il Piano di mobilità sostenibile metropolitano per una pianificazione e gestione integrata tra aree interne e città: il caso di Genova, Inu Edizioni, Urbanistica DOSSIER, Vol. 13. 
[4] 3rd European Conference on Sustainable Urban Mobility Plans, 2016, Bremen Declaration on Sustainable Urban Mobility Planning in Europe, Germany.

[5] European Commission, 2013, Intelligent energy-Europe ii implementation report 2012.

[6] Ruggiero, T.E., Uses and gratifications theory in the 21 st century. Mass Communication and Society, 3(1), pp. 3-37, 2000. DOI: /10.1207/s15327825mcs0301_02.

[7] Albrechtsen, E., 2003, Security and Safety, Norwegian University of Science and Technology Journal.

[8] OECD Better Life Initiative, 2014, How's Life? 2013 Measuring Well-being, Paris.

[9] 48/2017, "Disposizioni urgenti in materia di sicurezza delle città" "Urgent provisions on the safety of cities".

[10] Candia, S. \& Pirlone, F., 2015, Cycling as best practice for urban renovation-Study case: The city of Genoa, CSE - CITY SAFETY ENERGY journal, ISSUE 1-2015, ISSN 2284-3418.

[11] Municipality of Genoa, 2010, Piano Urbano della Mobilità Genovese.

[12] Municipality of Genoa, 2015, Riqualificazione urbana e legalità. 